NASA/TM-1999-208911

ARL-TR-1692
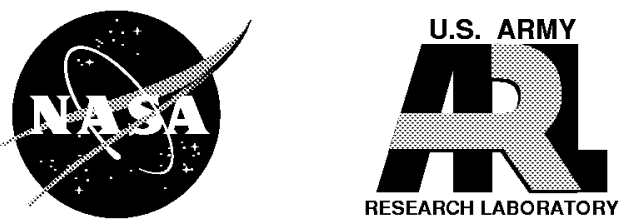

Oxygen Diffusion and Reaction Kinetics in Continuous Fiber Ceramic Matrix Composites

Michael C. Halbig

U.S. Army Research Laboratory, Lewis Research Center, Cleveland, Ohio

Andrew J. Eckel

Lewis Research Center, Cleveland, Ohio

James D. Cawley

Case Western Reserve University, Cleveland, Ohio 
Since its founding, NASA has been dedicated to the advancement of aeronautics and space science. The NASA Scientific and Technical Information (STI) Program Office plays a key part in helping NASA maintain this important role.

The NASA STI Program Office is operated by Langley Research Center, the Lead Center for NASA's scientific and technical information. The NASA STI Program Office provides access to the NASA STI Database, the largest collection of aeronautical and space science STI in the world. The Program Office is also NASA's institutional mechanism for disseminating the results of its research and development activities. These results are published by NASA in the NASA STI Report Series, which includes the following report types:

- TECHNICAL PUBLICATION. Reports of completed research or a major significant phase of research that present the results of NASA programs and include extensive data or theoretical analysis. Includes compilations of significant scientific and technical data and information deemed to be of continuing reference value. NASA's counterpart of peerreviewed formal professional papers but has less stringent limitations on manuscript length and extent of graphic presentations.

- TECHNICAL MEMORANDUM. Scientific and technical findings that are preliminary or of specialized interest, e.g., quick release reports, working papers, and bibliographies that contain minimal annotation. Does not contain extensive analysis.

- CONTRACTOR REPORT. Scientific and technical findings by NASA-sponsored contractors and grantees.
- CONFERENCE PUBLICATION. Collected papers from scientific and technical conferences, symposia, seminars, or other meetings sponsored or cosponsored by NASA.

- SPECIAL PUBLICATION. Scientific, technical, or historical information from NASA programs, projects, and missions, often concerned with subjects having substantial public interest.

- TECHNICAL TRANSLATION. Englishlanguage translations of foreign scientific and technical material pertinent to NASA's mission.

Specialized services that complement the STI Program Office's diverse offerings include creating custom thesauri, building customized data bases, organizing and publishing research results ... even providing videos.

For more information about the NASA STI Program Office, see the following:

- Access the NASA STI Program Home Page at http://www.sti.nasa.gov

- E-mail your question via the Internet to help@sti.nasa.gov

- Fax your question to the NASA Access Help Desk at (301) 621-0134

- Telephone the NASA Access Help Desk at (301) 621-0390

- Write to:

NASA Access Help Desk

NASA Center for AeroSpace Information 7121 Standard Drive

Hanover, MD 21076 
NASA/TM-1999-208911

ARL-TR-1692
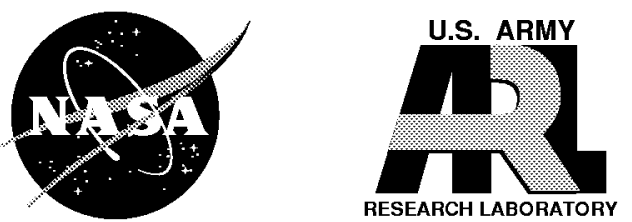

\section{Oxygen Diffusion and Reaction Kinetics in Continuous Fiber Ceramic Matrix Composites}

Michael C. Halbig

U.S. Army Research Laboratory, Lewis Research Center, Cleveland, Ohio

Andrew J. Eckel

Lewis Research Center, Cleveland, Ohio

James D. Cawley

Case Western Reserve University, Cleveland, Ohio

Prepared for the

22nd Annual Conference on Composites, Advanced Ceramics, Materials, and Structures sponsored by the American Ceramics Society

Cocoa Beach, Florida, January 17-21, 1998

National Aeronautics and

Space Administration

Lewis Research Center 
Trade names or manufacturers' names are used in this report for identification only. This usage does not constitute an official endorsement, either expressed or implied, by the National Aeronautics and Space Administration.

Available from

NASA Center for Aerospace Information 7121 Standard Drive

Hanover, MD 21076

Price Code: A03
National Technical Information Service 5285 Port Royal Road Springfield, VA 22100 Price Code: A03 


\title{
OXYGEN DIFFUSION AND REACTION KINETICS IN CONTINUOUS FIBER CERAMIC MATRIX COMPOSITES
}

Michael C. Halbig, Army Research Laboratory, Vehicle Technology Center, 21000 Brookpark Rd., Cleveland, OH 44135

Andrew J. Eckel, NASA Lewis Research Center, 21000 Brookpark Rd., Cleveland, OH 44135

James D. Cawley, Case Western Reserve University, 10900 Euclid Ave., 500 White Bld., Cleveland, OH 44106

\begin{abstract}
Previous stressed oxidation tests of $\mathrm{C} / \mathrm{SiC}$ composites at elevated temperatures $\left(350^{\circ} \mathrm{C}\right.$ to $1500^{\circ} \mathrm{C}$ ) and sustained stresses (69 MPa and $172 \mathrm{MPa}$ ) have led to the development of a finite difference cracked matrix model. The times to failure in the samples suggest oxidation occurred in two kinetic regimes defined by the rate controlling mechanisms (i.e. diffusion controlled and reaction controlled kinetics). Microstructural analysis revealed preferential oxidation along asfabricated, matrix microcracks and also suggested two regimes of oxidation kinetics dependent on the oxidation temperature. Based on experimental results, observation, and theory, a finite difference model was developed. The model simulates the diffusion of oxygen into a matrix crack bridged by carbon fibers. The model facilitates the study of the relative importance of temperature, the reaction rate constant, and the diffusion coefficient on the overall oxidation kinetics.

\section{INTRODUCTION}

Ceramic matrix composites, specifically continuous carbon fibers in a silicon carbide matrix, are proposed for high-temperature structural applications due to their high-strength to density ratios and ability to withstand high temperatures. High temperature capability allows engines to operate more efficiently, and with a reduction in the complex cooling systems often required for metallic alloys. Performance also is increased by weight reductions from lighter materials. Fiber reinforcement of the ceramic matrix allows the inherently brittle material to fail in a more graceful manner due to crack bridging and fiber pull-out. These properties make ceramic matrix composites ideal materials for inert environments, however, carbon fiber reinforced ceramic matrix composites are prone to corrosion in oxidizing environments.

Many studies of the oxidation of carbon fibers and pyrocarbon interphases in ceramic matrix composites involve thermogravimetric analysis (TGA) in which weight loss of the composite is monitored over time [1,2,3,4]. These types of studies can provide valuable information. However, the oxidation of the carbon constituents in the composite for unstressed and stressed states is very different. In an unstressed state, silica forms near $1200^{\circ} \mathrm{C}$ and cracks close near the processing temperature. These effects protect the interior of the composite from the outside environment $[2,4,5]$. However, in real application conditions, wide temperature ranges and stresses will prevent cracks from sealing.

The oxidation of carbon fibers in a $\mathrm{SiC}$ matrix has been studied experimentally in the stressed state [6]. Temperatures ranged from $350^{\circ} \mathrm{C}$ to $1500^{\circ} \mathrm{C}$ and stresses of $69 \mathrm{MPa}(10 \mathrm{ksi})$ or $172 \mathrm{MPa}(25 \mathrm{ksi})$ were applied. Although weight could not be monitored as in TGA experiments, the times and strains to failure of the composites provided an indication of the extent of oxidation.
\end{abstract}


Times to failure suggested two regions of oxidation kinetics with a strong dependence on temperature. In the temperature range of $350^{\circ} \mathrm{C}-750^{\circ} \mathrm{C}$, times to failure dropped sharply as temperature was increased. Samples went from surviving beyond $25 \mathrm{hr}$. with a high residual strength to failing in 91 minutes at $69 \mathrm{MPa}$ and in 22 minutes at the higher stress of $172 \mathrm{MPa}$ for temperatures of $750^{\circ} \mathrm{C}$. In the higher temperature range of $1000^{\circ} \mathrm{C}-1500^{\circ} \mathrm{C}$, temperature differences did not have as significant an effect on sample life. Sample lives remained near the same level as those at $750^{\circ} \mathrm{C}$ with some deviations in times to failure across the higher temperature range.

The effects of oxidation were also determined from analysis of polished cross-sections and fracture surfaces using optical and scanning electron microscopes. Oxidation was observed to occur preferentially along microcracks. Polished cross-sections of samples tested in the lower temperature range showed oxidation was relatively minimal and occurred in a rough, uneven pattern near the edges, but oxidation was also observed deep into the interior of the section, suggesting slow oxidation kinetics. Sections from samples tested in the higher temperature range showed oxidation occurring primarily along the edges in a uniform manner so that a reaction front could be seen. This gave a shrinking core type of effect as outer fibers were consumed as the oxidation process moved inward. This pattern along with the observation that fibers deep in the interior of the sample remained free of attack suggests the oxidation kinetics are much faster than in the lower temperature range. This change in the rate controlling mechanism from the lower temperature regime to the higher temperature regime has been attributed to a shift from the kinetics being reaction rate limited to being diffusion limited. These experimental results were used to provide a basis for developing a model so that a better understanding of diffusion controlled and reaction controlled kinetics could be gained.

A finite difference model was developed which simulates the diffusion of oxygen into a matrix crack bridged by an array of carbon fibers. The model provides a visual, qualitative and quantitative basis for understanding the oxidation kinetics. The influence of important variables: temperature (T), diffusion coefficient (D), and reaction rate constant $(\mathrm{K})$, are studied.

By obtaining a better understanding of the oxidation kinetics of carbon fibers in a ceramic matrix, the best approaches for protecting against oxidation can be determined depending on the application conditions: environment, temperature, stresses and required component lives. One possible approach for protecting the fibers might involve applying a less reactive interphase to the fiber. Another may be to include an oxidation inhibitor in the matrix that will react with oxygen to form oxides or glasses to seal cracks or to consume oxygen to provide more time before the carbon is attacked. Still another approach could be to identify external seal coatings that can better protect the interior of the material. One approach may be preferred over another due to exposure conditions, cost and/or mission requirements.

\section{THEORY}

The related theory used in developing the finite difference, cracked matrix model will be briefly discussed. In a ceramic matrix composite, oxygen diffuses down a pore or crack and reacts with carbon to form an oxide (either carbon monoxide or carbon dioxide). The oxide then diffuses out of the pore to the atmosphere. See Figure 1.

$$
\begin{aligned}
& \mathrm{O}_{2}+\mathrm{C} \rightarrow \mathrm{CO}_{2} \\
& \mathrm{O}_{2}+2 \mathrm{C} \rightarrow 2 \mathrm{CO}
\end{aligned}
$$

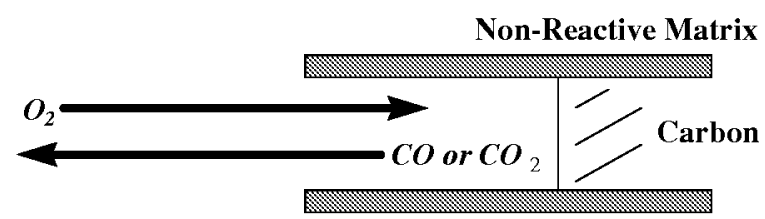

Figure 1. Oxygen diffusing into a pore and reacting with carbon. 
The oxidation kinetics for the recession of carbon can be described by the linearparabolic rate law:

$\frac{\mathrm{x}^{2}}{\mathrm{k}_{\mathrm{p}}}+\frac{\mathrm{x}}{\mathrm{k}_{\mathrm{l}}}=\mathrm{t}$

where $\mathrm{x}(\mathrm{m})$ is the recession distance of the carbon, $\mathrm{k}_{\mathrm{p}}$ is the parabolic rate constant $\left(\mathrm{m}^{2} / \mathrm{sec}\right), \mathrm{k}_{\mathrm{l}}$ is the linear rate constant $(\mathrm{m} / \mathrm{sec})$ and $\mathrm{t}$ is time $(\mathrm{sec})$.

The parabolic and linear rate constants can be related to more familiar mass transport constants, the diffusion coefficient and the reaction rate constant respectively. Only the relevant equations will be discussed. More thorough discussions and derivations can be found in papers by Eckel et al. [7] and Glime et al. [8].

When the linear term in equation (1) dominates and carbon dioxide is the evolving oxide, the equation for the recession distance is expressed as [7]:

$\mathrm{x}=\mathbf{t}^{1 / 2} \mathrm{k}_{\mathrm{p}}^{1 / 2}=\mathbf{t}^{1 / 2}\left(2 \mathrm{D} \mathrm{C}_{\mathrm{ox}} / \rho_{\mathrm{c}}\right)$ such that $\mathrm{k}_{\mathrm{p}}=\left(2 \mathrm{D} \mathrm{C} \mathrm{Cx}_{\mathrm{ox}} / \rho_{\mathrm{c}}\right)$

where $\mathrm{D}$ is the diffusion coefficient of oxygen in the pore $\left(\mathrm{m}^{2} / \mathrm{sec}\right), \mathrm{C}_{\mathrm{ox}}$ is the oxygen concentration of the atmosphere $\left(\mathrm{mol} / \mathrm{m}^{3}\right)$ and $\rho_{c}$ is the molar density of carbon $\left(\mathrm{mol} / \mathrm{m}^{3}\right)$.

In the case where carbon monoxide is the reaction product, Equation (2) for the recession distance will have a different form. However, the particular oxide that forms and the exact value for the diffusion coefficient is not of critical importance in this discussion and in the model. The main concern at this point in the development of the model is to identify trends. The discussion does not consider Knudsen effects in which molecular-wall collisions are more frequent than intermolecular collisions. Knudsen effects are not a factor until the pore becomes as small as $0.1 \mu \mathrm{m}$ [7]. In the material studied, typical cracks in the matrix and seal coating are on the order of $1 \mu \mathrm{m}$.

The second limiting case occurs when $\mathrm{k}_{\mathrm{p}}$ is much larger than $\mathrm{k}_{\mathrm{l}}$. The recession distance can be expressed as [8]:

$\mathrm{x}=\mathrm{t} \mathrm{k}_{\mathrm{l}}=\mathrm{t} \mathrm{K} \mathrm{C}_{\mathrm{ox}} / \rho_{\mathrm{c}} \quad$ such thatk $=\mathrm{K} \mathrm{C}_{\mathrm{ox}} / \rho_{\mathrm{c}}$

The above equation takes an alternate form when the oxygen concentration is substituted by the oxygen partial pressure, $\chi$, times the total concentration of gas molecules in the atmosphere, $\mathrm{C}_{\mathrm{T}}\left(\mathrm{mol} / \mathrm{m}^{3}\right)$. The total concentration can be substituted using the ideal gas law so that Equation (3) becomes [7]:

$\mathrm{k}_{\mathrm{l}}=\left(1 / \rho_{\mathrm{c}}\right)\left(\chi \mathrm{C}_{\mathrm{T}}\right)(\mathrm{K})=\left(1 / \rho_{\mathrm{c}}\right)(\chi \mathrm{P} / \mathrm{RT}) \mathrm{K}$

where $\mathrm{P}$ is pressure $(\mathrm{Pa}), \mathrm{R}$ is the gas constant $(\mathrm{J} / \mathrm{mol} \mathrm{K})$, and $\mathrm{T}$ is the absolute temperature $(\mathrm{K})$. Substituting values for $\mathrm{k}_{\mathrm{p}}$ and $\mathrm{k}_{\mathrm{l}}$, Equation (1) becomes

$\mathrm{t}=\frac{\mathrm{x}^{2}}{\mathrm{k}_{\mathrm{p}}}+\frac{\mathrm{x}}{\mathrm{k}_{\mathrm{l}}} \quad=\frac{\mathrm{x}^{2}}{\left(2 \mathrm{D} \mathrm{C_{ \textrm {ox } } / \rho _ { \mathrm { c } } )}\right.}+\frac{\mathrm{x}}{\left(1 / \rho_{\mathrm{c}}\right)(\chi \mathrm{P} / \mathrm{RT}) \mathrm{K}}$

The diffusion coefficient, D, can be obtained from Chapman-Enskog kinetic theory [9] and the reaction rate constant, $\mathrm{K}$, can be expressed in an Arrhenius form: 


$$
\mathrm{D}_{\mathrm{AB}}=\left(5.9543 \times 10^{-24}\right) \frac{\mathrm{T}^{3 / 2}\left(1 / \mathrm{M}_{\underline{A}}+1 / \mathrm{M}_{\underline{B}}\right)^{1 / 2}}{\mathrm{P} \sigma^{2}{ }_{\mathrm{AB}} \Omega_{\mathrm{AB}}}, \quad \mathrm{K}=\mathrm{k}_{\mathrm{o}} \exp (-\mathrm{Q} / \mathrm{RT}) \quad \text { (6) \& (7) }
$$

where $D_{A B}\left(\mathrm{~m}^{2} / \mathrm{sec}\right)$ is the diffusion coefficient of gas $A$ (oxygen) diffusing in the stationary or stagnant atmosphere of gas $B$ (oxide), $T$ is temperature $(K), M_{A}$ and $M_{B}$ are the molecular weights of gases $\mathrm{A}$ and $\mathrm{B}(\mathrm{kg} / \mathrm{mol})$, and $\mathrm{P}$ is pressure (Pa). The symbols $\sigma_{\mathrm{AB}}(\mathrm{m})$ and $\Omega_{\mathrm{AB}}$ (dimensionless) are Leonard Jones potentials for the collision diameter and collision integral respectively. Q is the activation energy $(\mathrm{J} / \mathrm{mol})$.

From the above equations for the diffusion coefficient (6) and the reaction rate constant (7), it is seen that one of the two arguments in Equation (5) will dominate depending on temperature. The diffusion coefficient depends on $\mathrm{T}^{3 / 2}$, with the effect being even less when the decreasing molar density of the gas is considered with increasing temperature. The reaction rate constant varies exponentially with temperature when large activation energies are considered. It can be seen that Equation (5) describes a two step process occurring in series. Each step has the potential to limit the overall process. When the reaction rate constant is small and the diffusion coefficient is large, the process will be limited by the reaction rate, i.e. reaction controlled.

Oxygen will diffuse into the pore faster than it can react so that the pore becomes saturated in oxygen. However, if the diffusion coefficient is small compared to the reaction rate constant, carbon/oxygen reactions occur as soon as oxygen is supplied. In this case the process is controlled by the slower diffusion step, i.e. diffusion controlled.

\section{MODELING}

In order to gain a better understanding of the diffusion and reaction kinetics observed in the experiments, a finite difference model was developed. The physical setup of the model is an array of carbon fibers bridging a matrix crack, as illustrated in Figure 2. Figure 3 shows an example of an experimental observation of oxidation occurring along fibers bridging a crack, which is the physical situation on which the model is based.

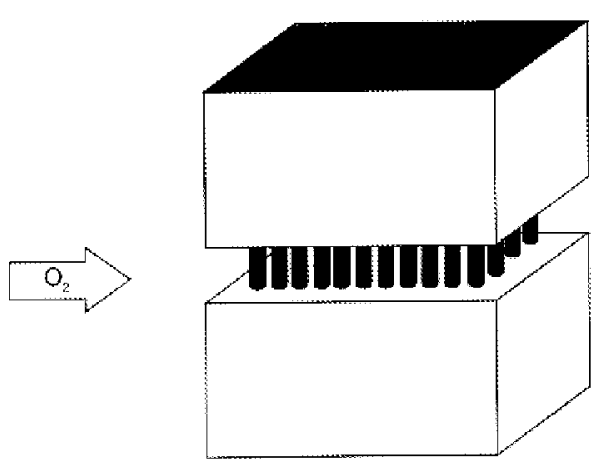

Figure 2. Fibers bridging a cracked matrix.

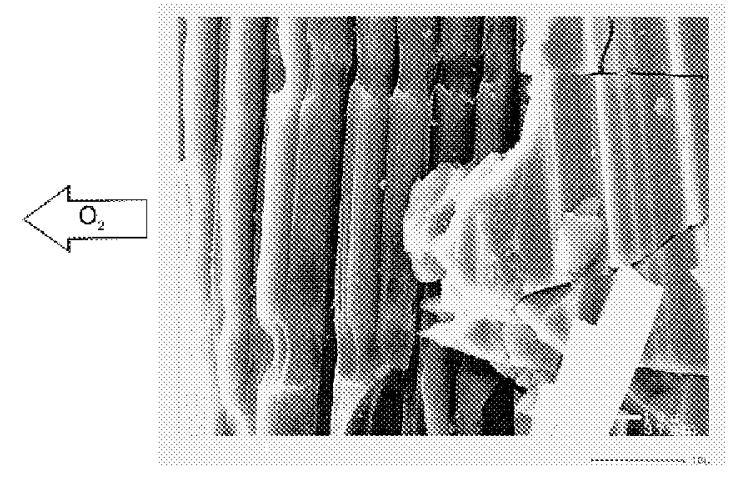

Figure 3. Oxidation of carbon fibers that bridge matrix cracks. 
A 2-Dimensional grid pattern was laid out as a 250×250 mesh of grids, which represents an open plane within the bridged space parallel to the two crack surfaces of the matrix. Grids within the mesh are designated as either open space containing the diffusing gases, or as carbon containing grids. Carbon fibers are represented as a $12 \times 12$ array of fibers which have diameter of 10 grids. Fibers are spaced a distance of 10 grids from one another and from the outer edge. One quarter of the grid pattern is shown in Figure 4.

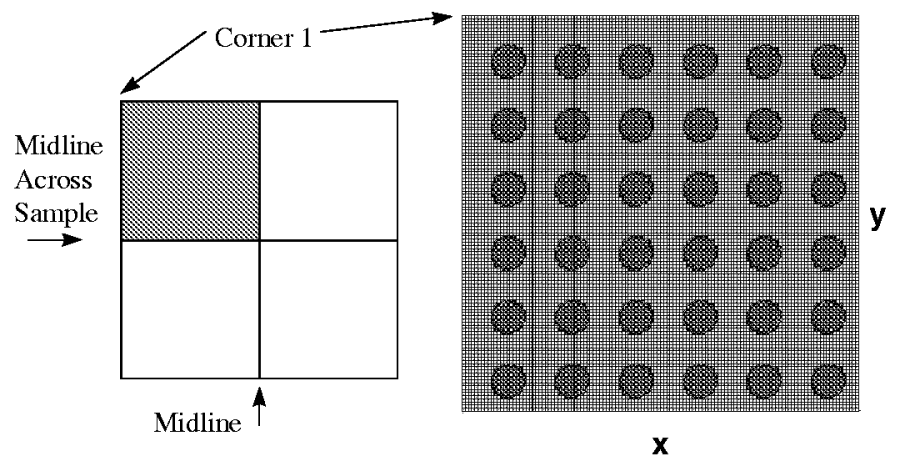

Figure 4. One quarter plot of the matrix pattern (right) orientated as shown on the left.

In the model, the outer boundary has a initial oxygen concentration arbitrarily set at 1.0 $\mathrm{mol} / \mathrm{cm}^{3}$, which is assumed to stay constant due to the atmospheric conditions. Oxygen diffuses into the matrix. Concentrations are calculated throughout the matrix based on oxidation kinetics in which both reactivity and diffusion are both dependent on temperature and one may be limiting the overall process. Plots of oxygen concentration as a function of grid position showing gradients high or low in oxygen concentration will give clues to the limiting step in the two step process.

When mass transport occurs by convection, the flux is given by,

$$
\text { Flux }=\mathrm{J}=\mathrm{K}\left(\mathrm{C}_{\mathrm{A}, 1}-\mathrm{C}_{\infty}\right)
$$

where $\mathrm{C}_{\mathrm{A}, 1}$ (which has a value of $0 \mathrm{~mol} / \mathrm{cm}^{3}$ ) is the oxygen concentration at the reaction front or of the carbon edge (carbon containing grid) and $\mathrm{C}_{\infty}$ is the oxygen concentration in the bulk gas (oxygen containing grid).

When mass transport occurs by diffusion, the flux is given by,

$$
\text { Flux }=\mathrm{J}=\mathrm{D}\left(\mathrm{C}_{2}-\mathrm{C}_{1}\right) / \Delta \mathrm{x}
$$

where $\left(\mathrm{C}_{2}-\mathrm{C}_{1}\right)$ is the difference in oxygen concentration within the stagnant gas across some distance, $\Delta x$. An important unitless parameter, the Sherwood number, Sh, is obtained from the ratio of the fluxes per the driving force due to concentration differences,

$\mathrm{Sh}=\mathrm{F}($ convection $) / \Delta \mathrm{C} / \mathrm{F}($ diffusion $) / \Delta \mathrm{C}=\mathrm{K} \Delta \mathrm{x} / \mathrm{D}$

The Sherwood number will be used extensively throughout the model. For low Sh values, low temperatures, the kinetics are reaction controlled, and for high Sh values, high temperatures, the kinetics are diffusion controlled. 
Detail of the grid pattern showing half of a carbon fiber and open pore space is illustrated in Figure 5. The oxygen concentration of a grid is determined by sampling from its four neighbors. The fluxes between the central grid and its 4 neighbors are added. The net flux into and out of the central grid is zero. The flux equation is then solved for the concentration of the central grid. When all four neighbors are within the stagnant gas as for grid 1, mass transport occurs by diffusion and the equation for the oxygen concentration of this grid is

$\mathrm{C}(\mathrm{i}, \mathrm{j})=\underline{\text { sum of oxygen concentrations }}$ 4

When one of the neighboring grids contains carbon, as for grid 2 in Figure 5, mass transport occurs through convection between the central grid and the carbon containing grid. For the other three grids mass transport occurs by diffusion. The equation for the oxygen concentration of the central grid becomes
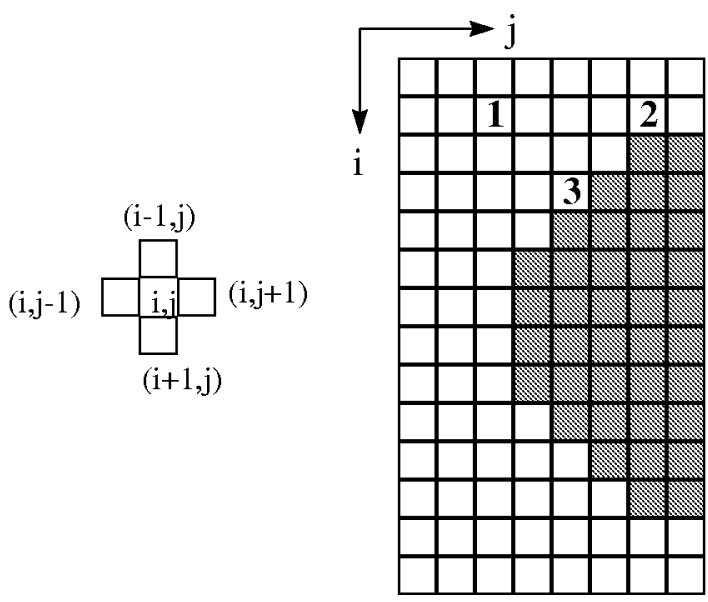

Figure 5. Grid pattern for model.

$C(i, j)=[C(i, j-1)+C(i-1, j)+C(i, j+1)]+S h^{*} C(i+1, j)$ $(3+\mathrm{Sh})$

When two neighbors contain carbon and two contain the stagnant gas, as in grid 3, the equation becomes

\section{$C(i, j)=[C(i, j-1)+C(i-1, j)]+\operatorname{Sh}[C(i, j+1)+C(i+1, j)]$$$
(2+2 \mathrm{Sh})
$$

The program is run for several different Sh values: $0.0001,0.001,0.01,0.1,1,10$. Oxygen concentrations are determined throughout the bridged section based on the boundary condition and the equations for oxygen concentration. The program runs until a quasi-steady state is reached. Note the program does not remove carbon by reaction at this point; future development of the program will remove carbon and continuously recalculate oxygen concentrations so that oxidation patterns relating to diffusion controlled and reaction controlled kinetics are obtained. The program may be thought of at this point as having a continuous supply of oxygen and carbon, where oxygen concentrations throughout the section are calculated until steady state is reached. It should be pointed out that since oxidation really occurs in 3-dimensions, the 2 - dimensional model does not consider or allow the analysis of certain factors. These include 3rd dimensional effects such as fiber recession and the supply of oxygen through open channels where the carbon fiber has been consumed.

The obtained data files for a given Sherwood number were used to prepare plots of the oxygen concentrations across the interior of the fiber bridged matrix. Gradients in oxygen concentration across the bridged section show regions where oxygen supply is low or high and give indications about the reactivity. Figure 6 shows the oxygen concentrations for one-quarter of the whole section for a relatively high Sherwood number, $\mathrm{Sh}=0.1$. The 3 -D effect of the plot is due to plotting oxygen concentrations across the 2-D surface. It is seen that oxygen concentrations drop sharply upon diffusion into the matrix. This suggests that the carbon is very reactive and reacts with oxygen as soon as it is supplied. The overall oxidation process is limited by the slow supply of oxygen to the reaction process at the carbon/oxygen interface, i.e. diffusion controlled kinetics. The case for a relatively low Sherwood number, $\mathrm{Sh}=0.001$, is shown in Figure 7 . The plot shows that the reactions are slow so that oxygen is able to diffuse into the interior in high 
concentrations and saturate the interior. In this case, the two step process of oxygen diffusion and carbon/oxygen reactions is limited by the slower reaction process, reaction controlled kinetics.
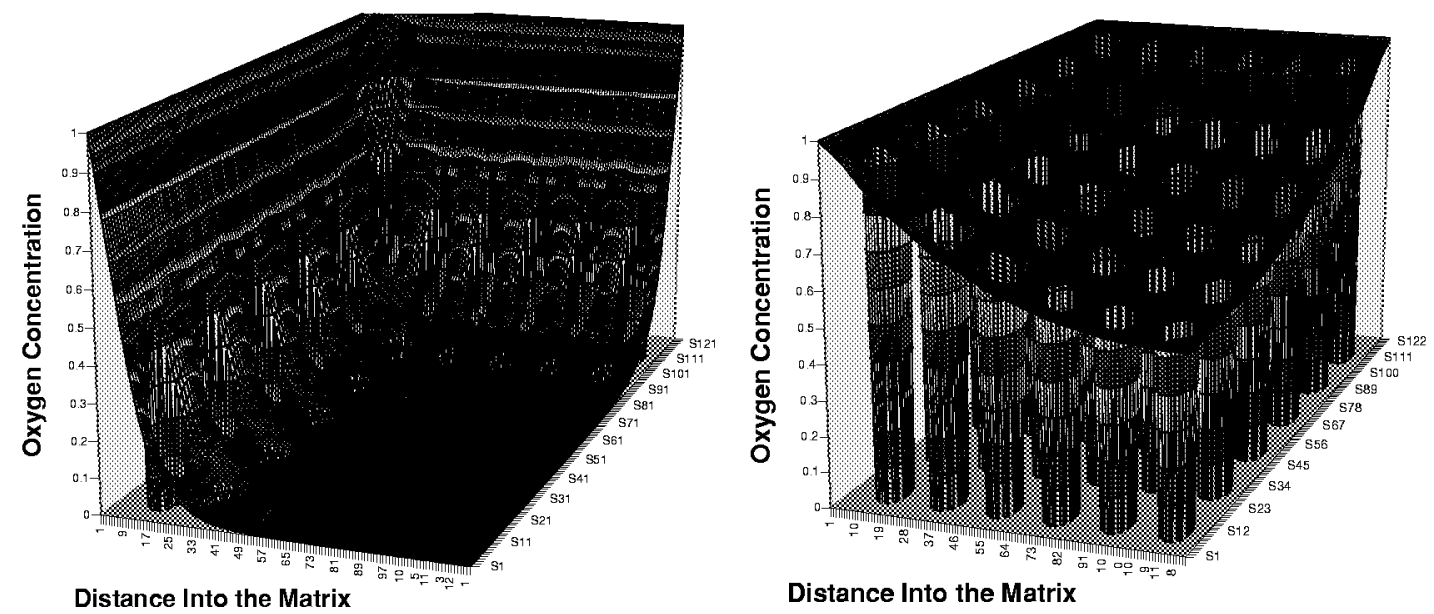

Distance Into the Matrix

Figure 6 (left) $\mathrm{Sh}=0.1$. Figure 7 (right) $\mathrm{Sh}=0.001$. One-quarter plots of a $250 \times 250$ matrix with a $12 \times 12$ fiber array. Interated to equilibrium.

In the two previous figures, the curves at the edges of the plots represent the oxygen concentration through one-half of the thickness of the section. Full plots of the oxygen concentrations across the midline are shown in Figure 8 for several Sherwood numbers. High Sh values illustrate how the process is diffusion controlled. Oxygen is quickly consumed before it can enter into the interior of the matrix. Low Sh values illustrate how the kinetics are reaction controlled. Carbon/oxygen reactions are slow so that there is a high concentration of oxygen throughout the section.

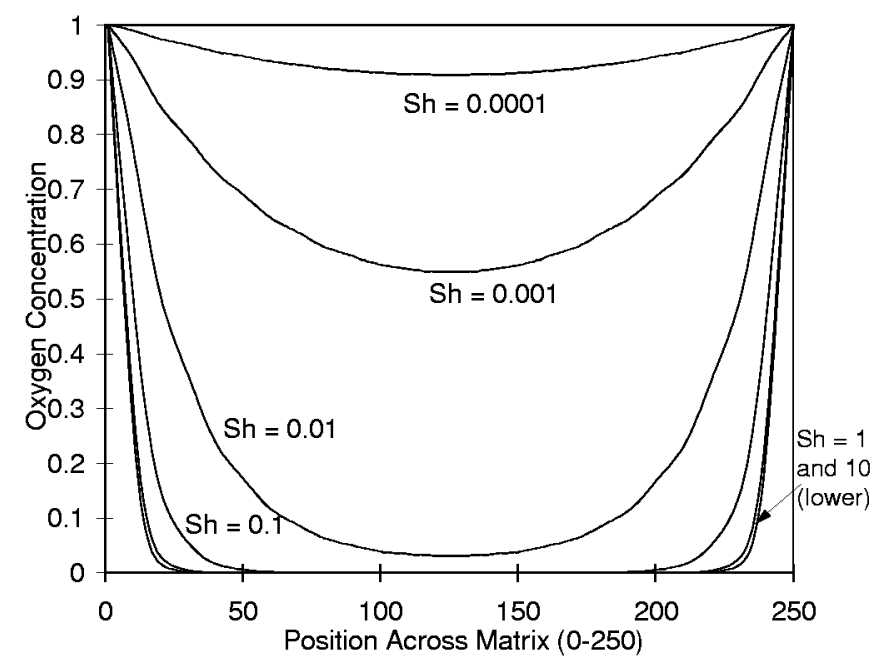

$$
\mathrm{Sh}=\frac{\Delta \mathrm{xK}}{\mathrm{D}}
$$

Reaction Controlled

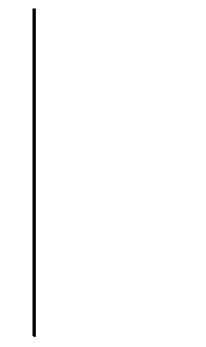

Diffusion Controlled

Figure 8. Oxygen concentrations across the center of the surface for several Sherwood (Sh) values. SUMMARY

Experimental studies on $\mathrm{C} / \mathrm{SiC}$ composite material exposed to stressed oxidation conditions suggested two types of oxidation kinetics. Lives of the samples were very temperature 
dependent in the range of $350^{\circ} \mathrm{C}-750^{\circ} \mathrm{C}$, while there was less of a temperature dependence in the range of $1000^{\circ} \mathrm{C}-1500^{\circ} \mathrm{C}$. Microstructural analysis revealed a different type of oxidation pattern for each temperature range. The related theories for carbon recession, reaction kinetics, diffusion kinetics, flux due to mass transport, and Sherwood numbers were reviewed. Temperature effects on the reaction rate constant and the diffusion coefficient were also discussed. Based on experimental observation, and theory, a finite difference model was presented.

\section{CONCLUSIONS}

The oxidation of carbon fibers in a ceramic matrix is a two step process with a varying temperature dependence. The overall process will be limited by the slower step. The kinetics can be analyzed by studying the diffusion of oxygen and determining its concentration throughout the section. The finite difference model is in good agreement with experimental results in suggesting two types of kinetics. The model supports the conclusion that the kinetics are reaction controlled at low temperatures, and diffusion controlled at high temperatures.

The next steps in the model development include the removal of carbon as it reacts with oxygen. In the case of diffusion controlled kinetics, i.e. high Sherwood number, oxygen will oxidize away the outer fibers first, then continue to move inward so that a shrinking core effect is seen. For reaction controlled kinetics, i.e. low Sherwood number, there will be a generalized oxidation of fibers throughout the section. Another developmental step for the model will include putting an element around the fibers to represent the interphase. Different reactivities of the fiber and interphase can then be considered.

\section{REFERENCES}

1. S. Goujard, L. Vandenbuckle, H. Tawil, "The Oxidation Behavior of Two- and ThreeDimensional C/SiC Thermostructural Materials protected by Chemical Vapor Deposition Polylayers Coatings," Journal of Materials Science 29, pp. 6212-6220, (1994).

2. Frank Lamouroux, Gerald Camas, and Jacques Thebault, "Kinetics and Mechanisms of Oxidation of 2D Woven C/SiC Composites: I, Experimental Approach," J. Am. Ceram. Soc., 77 [8] 2049-57 (1994).

3. F. Lamouroux, X. Bourrat, R. Nasalain, J. Sevely, "Structure/Oxidation Behavior Relationship in the Carbonaceous Constituents of 2-D/PyC/SiC Composites," Carbon, Vol. 31, No. 8, pp. 1273$1288,1993$.

4. Ludovic Filipuzzi, Gerald Camus, and Roger Naslaim, "Oxidation Mechanisms and Kinetics of 1D-SiC/C/SiC Composite Materials: 1, An Experimental Approach," J. Am. Ceram. Soc., 77 [2], pp. 459-466, 1994.

5. C. Vix -Guterl, J. Lahaye and P. Ehrburger, "Reactivity of Silicon Carbide and Carbon with Oxygen in Thermostructural Composites," Carbon, Vol. 31, No. 4, pp. 629-635, 1993.

6. Michael C. Halbig, Andrew J. Eckel, James D. Cawley and David N. Brewer, "Stressed Oxidation of C/SiC Composites," Proceedings of the $21^{\text {st }}$ Annual Conference on Composites, Advanced Ceramics, Materials and Structures, Cocoa Beach, Florida, January 12-16, 1997.

7. Andrew J. Eckel, James D. Cawley and Triplicane A. Parthasarathy, "Oxidation Kinetics of a Continuous Carbon Phase in a Nonreactive Matrix," J. Am. Ceram. Soc., 78 [4] 972-80 (1995). 8. William H. Glime and James D. Cawley, "Oxidation of Carbon Fibers and Films in Ceramic Matrix Composites: A Weak Link Process," Carbon, Vol. 33, No. 8, pp. 1053-1060, 1995.

9. W. Geankoplis, Mass Transport Phenomena, Ohio State U. Bookstore, Columbus, OH, 1978. 
\begin{tabular}{l|l|l}
\hline 1. AGENCY USE ONLY (Leave blank) & 2. REPORT DATE & 3. REPORT TYPE AND DATES COVERED
\end{tabular}

\section{TITLE AND SUBTITLE}

February 1999

Technical Memorandum

Oxygen Diffusion and Reaction Kinetics in Continuous Fiber

Ceramic Matrix Composites

6. AUTHOR(S)

WU-523-21-13-00

Michael C. Halbig, Andrew J. Eckel, and James D. Cawley

1L161102AH45

7. PERFORMING ORGANIZATION NAME(S) AND ADDRESS(ES)

NASA Lewis Research Center

Cleveland, Ohio 44135-3191

and

U.S. Army Research Laboratory

5. FUNDING NUMBERS

Cleveland, Ohio 44135-3191

9. SPONSORING/MONITORING AGENCY NAME(S) AND ADDRESS(ES)

National Aeronautics and Space Administration

Washington, DC 20546-0001

and

U.S. Army Research Laboratory

Adelphi, Maryland 20783-1145

8. PERFORMING ORGANIZATION

REPORT NUMBER

E-11540

11. SUPPLEMENTARY NOTES

Prepared for the 22nd Annual Conference on Composites, Advanced Ceramics, Materials, and Structures sponsored by the American Ceramics Society, Cocoa Beach, Florida, January 17-21, 1998. Michael C. Halbig, U.S. Army Research Laboratory, NASA Lewis Research Center; Andrew J. Eckel, NASA Lewis Research Center; James D. Cawley, Case Western Reserve University, 10900 Euclid Avenue, 500 White Building, Cleveland, Ohio 44106. Responsible person, Michael C. Halbig, organization code 5130, (216) 433-2651.

12a. DISTRIBUTION/AVAILABILITY STATEMENT

12b. DISTRIBUTION CODE

Unclassified - Unlimited

Subject Category: Categories: 27 and 64

Distribution: Nonstandard

This publication is available from the NASA Center for AeroSpace Information, (301) 621-0390.

13. ABSTRACT (Maximum 200 words)

Previous stressed oxidation tests of $\mathrm{C} / \mathrm{SiC}$ composites at elevated temperatures $\left(350^{\circ} \mathrm{C}\right.$ to $\left.1500^{\circ} \mathrm{C}\right)$ and sustained stresses (69 $\mathrm{MPa}$ and $172 \mathrm{MPa}$ ) have led to the development of a finite difference cracked matrix model. The times to failure in the samples suggest oxidation occurred in two kinetic regimes defined by the rate controlling mechanisms (i.e. diffusion controlled and reaction controlled kinetics). Microstructural analysis revealed preferential oxidation along as-fabricated, matrix microcracks and also suggested two regimes of oxidation kinetics dependent on the oxidation temperature. Based on experimental results, observation, and theory, a finite difference model was developed. The model simulates the diffusion of oxygen into a matrix crack bridged by carbon fibers. The model facilitates the study of the relative importance of temperature, the reaction rate constant, and the diffusion coefficient on the overall oxidation kinetics.

\section{SUBJECT TERMS}

Ceramic matrix composites; Oxidation kinetics

\begin{tabular}{|c|c|}
\hline $\begin{array}{c}\text { 17. SECURITY CLASSIFICATION } \\
\text { OF REPORT } \\
\text { Unclassified }\end{array}$ & $\begin{array}{c}\text { 18. SECURITY CLASSIFICATION } \\
\text { OF THIS PAGE } \\
\text { Unclassified }\end{array}$ \\
\hline
\end{tabular}

19. SECURITY CLASSIFICATION OF ABSTRACT

Unclassified
NASA TM-1999-208911

ARL-TR-1692 